\title{
Influence of dose rate on the radiolytic stability of a BTBP solvent for actinide(III)/lanthanide(III) separation
}

\author{
By A. Fermvik ${ }^{1, *}$, C. Ekberg ${ }^{1,2}$, S. Englund ${ }^{3}$, M. R. S. J. Foreman ${ }^{1,2}$, G. Modolo ${ }^{4}$, T. Retegan ${ }^{1}$ and G. Skarnemark ${ }^{1}$ \\ ${ }^{1}$ Nuclear Chemistry, Department of Chemical and Biological Engineering, Chalmers University, 41296 Gothenburg, Sweden \\ 2 Industrial Materials Recycling, Department of Chemical and Biological Engineering, Chalmers University, 41296 Gothenburg, Sweden \\ ${ }^{3}$ OKG AB, 57283 Oskarhamn, Sweden \\ ${ }^{4}$ Forschungszentrum Jülich GmbH, 52425 Jülich, Germany
}

(Received May 1, 2008; accepted in revised form December 19, 2008)

\section{Irradiation / Dose rate / Solvent extraction / Partitioning / Actinides / Lanthanides / Distribution ratio / \\ Separation factor}

Summary. The recently developed ligand MF2-BTBP dissolved in cyclohexanone is a promising solvent for the group separation of trivalent actinides(III) from the lanthanides(III). Its high stability against nitric acid has been demonstrated recently. Since the solvent is also exposed to a continuously high radiation level in the counter current process, the radiolytic stability of the solvent was examined in this study. Irradiation experiments were carried out up to an absorbed dose of $100 \mathrm{kGy}$ and the effect of the dose rate was investigated. The extraction behaviour for $\mathrm{An}(\mathrm{III}) / \mathrm{Ln}$ (III) separation was studied after radiolysis for evaluation. It was found that during high dose rate irradiation the extraction efficiency for both $\mathrm{Am}(\mathrm{III})$ and $\mathrm{Eu}(\mathrm{III})$ decreased significantly with increasing absorbed dose, whereas during the low dose rate irradiation the extraction efficiencies remained more or less at the same level.

\section{Introduction}

One important step in the partitioning and transmutation of spent nuclear fuel involves the separation of trivalent actinides (americium and curium) from trivalent lanthanides. The European research over the last decade, i.e. in the NEWPART, PARTNEW and the recent EUROPART programs [1-3], has resulted in the development of the combination of two partitioning processes. These are based on the co-separation of trivalent actinides and lanthanides (DIAMEX) by a diamide followed by the subsequent selective separation of trivalent actinides in the SANEX process (selective actinide extraction) [4]. One of the proposed SANEX processes includes liquid-liquid extraction using polycyclic nitrogen-based ligands dissolved in an organic diluent as solvent.

The goal is to selectively extract the actinides(III) from the feed solution into the organic phase, leaving all lanthanides in the raffinate. The extracting ligand should not only be able to selectively extract actinides, but also meet

\footnotetext{
*Author for correspondence (E-mail: anna.fermvik@chalmers.se).
}

a number of criterions such as being soluble in desired diluents, chemically stable, preferably completely incinerable (CHON-principle) [5], resistant towards hydrolysis and resistant towards radiolysis, a criterion that will be discussed in this paper.

A large number of heterocyclic N-donor SANEX extractants have been developed in the European research projects [6]. Unfortunately, most of them were only able to extract trivalent actinides from solutions of very low acidity and suffer from hydrolytic and radiolytic instability. One group of polycyclic nitrogen-based ligands that has been extensively studied regarding its extracting and separating capabilities is the BTBP (6,6'-bis-(5,6-dialkyl-1,2,4-triazin3 -yl)-[2,2']bipyridine) family [7].

BTBP's exhibit high affinity towards the trivalent actinides to be extracted from acidic solutions $(>1 \mathrm{~mol} / \mathrm{L}$ $\mathrm{HNO}_{3}$ ) and high separation factors over the lanthanides to be rejected [8]. Furthermore they show high chemical stability against nitric acid [9]. In this study, the radiolytic stability of one of the most recently developed ligands belonging to this family, MF2-BTBP (4-tert-butyl-6,6'-bis(5,5,8,8-tetramethyl-5,6,7,8-tetrahydro-benzo[1,2,4]triazin3 -yl)-[2,2']bipyridine), was studied (see Fig. 1).

An organic solvent used for one year in the industrial implementation of SANEX is expected to receive a total dose of between $100 \mathrm{kGy}$ and $1 \mathrm{MGy}$ [10]. This corresponds to a dose rate of $\sim 10-100 \mathrm{~Gy} / \mathrm{h}$. For the evaluation of the radiolytic stability of an organic solvent, not only the total received dose but also the dose rate is an important parameter

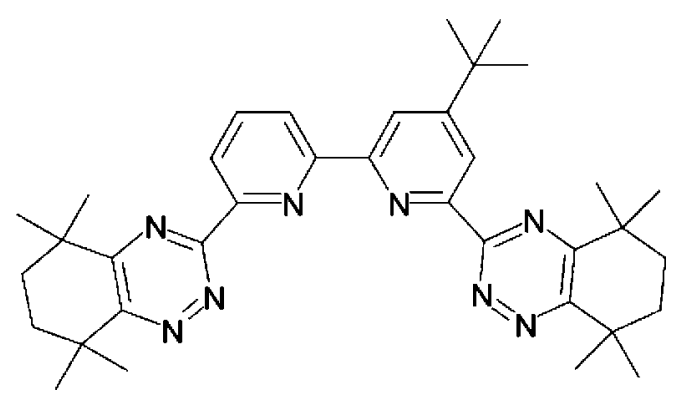

Fig. 1. Schematic picture of MF2-BTBP (4-tert-butyl-6,6'-bis-(5,5,8,8tetramethyl-5,6,7,8-tetrahydro-benzo[1,2,4]triazin-3-yl)-[2,2']-bipyridinyl) [17]. 
to test. In this work we report the effect of two different dose rates, and the changes in actinide(III) and lanthanide(III) extraction after various received doses were compared to evaluate these effects.

\section{Theory}

When discussing the hazards of ionizing radiation and its effect on matter, the unit of interest is often the absorbed dose. However, the total dose does not provide the whole story. For example, when it comes to health hazards and damages in human cells following exposure to radiation, the rate of the absorbed dose is also an important factor. With a long term exposure at a relatively low dose rate a much higher total dose $(\mathrm{mSv})$ can be received before reaching a number of health endpoint factors, such as $\mathrm{LD}_{50 / 60}$ and $10 \%$ increase in late effects, compared to a large dosage of radiation in a shorter period of time [11]. In the same way as the dose rate affects the severity of irradiation induced damage to a cell, an organic solution that is being exposed to a certain dose is likely to act differently depending on the dose rate of the irradiating source.

One characterization used to describe radiolysis is primary and secondary processes [12], also referred to as direct/indirect radiolysis [13]. Direct radiolysis is degradation caused by energy transfer from the radiation to the molecule of interest, while indirect radiolysis is a chemical reaction of free radicals and other species formed in the direct radiolysis. The latter reactions can theoretically proceed even after the irradiation has stopped. Species formed in direct and indirect radiolysis reactions have very short lifetimes $\left(10^{-12}-1 \mathrm{~s}\right)$ [14], thus the probability of this type of reactions occurring after the stop of the irradiation is low. After these short-lived species have disappeared, more stable reaction products with lifetimes in the region of $10-10^{9} \mathrm{~s}$ or more [14] are left and these may very well continue to react with solute molecules for a long period of time.

When proposing a model for the kinetic behaviour of compounds subjected to radiolysis in aqueous solution, Rice et al. [15] used other concepts to describe radiolytic reactions. Radicals can be divided into primary or secondary radicals, where primary radicals refer to radicals formed by water radiolysis and secondary radicals refer to radicals formed in a reaction between a primary radical and a solute or solvent molecule [15]. Hence, the terms primary and secondary are used in a slightly different way than above. The radiation processes are divided into consecutive or parallel processes, where consecutive processes involve reactions between primary radicals and solute molecules or reactions between primary radicals and secondary radicals [15]. Parallel processes involve reactions between a solute molecule and a secondary radical or reactions between two secondary radicals. It is stated that a lack of dose rate dependency suggests that the radiolysis mechanism is, to a large extent, consecutive in nature, while a variation with dose rate indicates a parallel mechanism. Rice's model includes assumptions such as that the fraction of diluent molecules by far exceeds that of the solute molecules and that the energy absorbed directly by the solute can be neglected. These assumptions are also valid for the experiments in this paper.
At higher dose rates the steady-state concentration of reactive species such as ions, radicals and excited species, is higher [14]. This means that there is a higher probability that these species react with each other [14], forming more species with longer half lives that may in turn react with solute molecules.

Water is by far the most studied diluent when it comes to radiolysis [16]. The major products of water radiolysis are hydrogen atoms, hydroxyl and perhydroxyl radicals, hydrogen peroxides and hydrated electrons [16]. All radiolysis experiments in this study have been performed by irradiating the organic phase alone, hence the experiments are not fully representative of process conditions. Many additional reactions and mechanism have to be taken into account when irradiating the two phases in contact with each other. Firstly, it is uncertain how the radiolysis products of the aqueous phase will react with the organic phase and its degradation products. Secondly, degradation products from the organic phase, such as radical ions et cetera, might transfer to the aqueous phase before reacting further.

The structure of MF2-BTBP [17], the molecule investigated in this study, resembles the structure of $\mathrm{CyMe}_{4}$-BTBP, which have proven to be relatively stable towards radiolysis [18]. MF2-BTBP efficiently extracts americium while leaving the europium in the aqueous phase. It is assumed that the extraction mechanisms for MF2-BTBP with $\mathrm{Am}^{3+}$ and $\mathrm{Eu}^{3+}$ are the same. Slope analysis of a curve plotting $\log D$ vs. $\log [\mathrm{MF} 2-\mathrm{BTBP}]$ showed similar values for Am and Eu [19]. Additionally, in EXAFS experiments, the same type of species were found in the organic phase for both $\mathrm{Am}^{3+}$ and $\mathrm{Eu}^{3+}$ with BTP [20], the precursor to the BTBP's. The extraction kinetics appears to be different for Am and $\mathrm{Eu}[19,21]$ but the reason for this is not yet established.

\section{Experimental}

\subsection{Chemicals, solutions and isotopes}

MF2-BTBP (see Fig. 1) was synthesized and provided by Reading University, UK [17]. Organic solutions were prepared by dissolving weighed quantities of MF2-BTBP in cyclohexanone (Merck KGaA, Darmstadt, Germany, 99\%). Nitric acid solutions were prepared by diluting concentrated nitric acid (Merck KGaA, Darmstadt, Germany) with ultrapure water ( $>18 \mathrm{M} \Omega$ ) produced by "Milli-Q gradient" provided by Millipore ${ }^{\circledR}$. The spike solution contained ${ }^{152} \mathrm{Eu}$ and ${ }^{241} \mathrm{Am}$. The radiotracers used for the experiments in Jülich, Germany, were provided by Isotopendienst M.Blaseg $\mathrm{GmbH}$, Waldburg, Germany, while the radiotracers used in Gothenburg, Sweden, were prepared from laboratory stock solutions [22].

\subsection{Irradiations}

A solvent containing $0.01 \mathrm{M}$ of MF2-BTBP in $30 \mathrm{~mL}$ cyclohexanone was irradiated to a total received dose of 80-100 kGy using two irradiation sources with different dose rates. The low dose rate was $\sim 15 \mathrm{~Gy} / \mathrm{h}$ and the irradiation was performed in a ${ }^{60} \mathrm{Co}$ cell (Gamma cell 220 from Atomic Energy of Canada Ltd.) at Chalmers University of Technology, Gothenburg, Sweden. The dose rate was 
calculated from a calibration certificate based on Fricke dosimetry. Photons emitted from ${ }^{60} \mathrm{Co}$ have an average energy of $1.2 \mathrm{MeV}$ [12]. The high dose rate was $1.2 \mathrm{kGy} / \mathrm{h}$ and the irradiation experiments were performed in the cooling pond of the DIDO research reactor at Forschungszentrum Jülich GmbH, Germany. This dose rate was simultaneously measured with cobalt glass dosimetry. The mean energy of the $\gamma$-spectrum of the spent fuel in the cooling pond was $0.8 \mathrm{MeV} . \gamma$-rays interact with matter in three different ways: photoelectric effect, Compton effect and pair production, and the relative contribution of the different interactions depends on the energy of the photons [12].

Since the total time of irradiation was very long for the solution placed in the ${ }^{60} \mathrm{Co}$ source in Sweden, $\sim 5400 \mathrm{~h}$, a reference solution was placed outside the source and corresponding samples were taken from this solution to establish possible effects due to ageing of the solution. No reference solution was used in the high dose rate experiments since the total time of irradiation was limited to $84 \mathrm{~h}$, and the measurements of the reference solution above were assumed to be valid also for the high dose rate experiments.

Samples were taken from the reference and irradiated solvents at various times. Before contact with aqueous phase, but after irradiation, the solvent was pre-equilibrated with $1 \mathrm{M} \mathrm{HNO}_{3}$, which was the base for the aqueous phase. $\mathrm{HNO}_{3}$ with no addition of radionuclides was in turn preequilibrated with pure cyclohexanone (not irradiated). This is important to notice, since the cyclohexanone in the samples may have degraded and does not possess the same properties as pure, fresh cyclohexanone. An option could be to pre-equilibrate the $\mathrm{HNO}_{3}$ with the irradiated and the reference solution respectively, but then the ligand may be present in the aqueous phase. It is also possible that some BTBP molecules are transferred to the aqueous phase during pre-equilibration, resulting in a lower concentration of the ligand and hence a lower distribution ratio $(D)$. In a previous study extraction experiments using preequilibration as described above were compared to experiments without any pre-equilibration [23]. No difference in distribution ratios was observed, indicating that the loss of ligand during pre-equilibration can be neglected. The solubility of the ligand in the aqueous phase was too low to be measured with spectrophotometric methods (detection limit: $\sim 10^{-5} \mathrm{M}$ ).

\subsection{Distribution ratio measurements}

\subsubsection{Low dose rate experiments}

Triple samples were taken from the irradiated solution and triple or double samples were taken from the reference solution. $500 \mu \mathrm{L}$ of organic phase was contacted for $5 \mathrm{~min}$ (vigorous manual shaking) with $500 \mu \mathrm{L}$ aqueous phase, comprising $1 \mathrm{M} \mathrm{HNO}_{3}$ and trace amounts of ${ }^{152} \mathrm{Eu}$ and ${ }^{241} \mathrm{Am}$. The samples were centrifuged for $10 \mathrm{~min}$ at $800 \mathrm{~g}$ and aliquots of $200 \mu \mathrm{L}$ from both phases were taken and analyzed with high-purity germanium detectors (Ortec, Gamma Analyst GEM 23195 or EG\&G Ortec). The contact time of 5 min manual shaking proved to be insufficient in order to reach equilibrium for europium. The time was kept the same for all sampling points. Differences in extrac- tion may occur anyway, due to variations in manual shaking technique and drop size.

\subsubsection{High dose rate experiments}

Samples of $400 \mu \mathrm{L}$ of organic phase were contacted for $1 \mathrm{~h}$ in a mechanical shaker with $400 \mu \mathrm{L}$ aqueous phase, comprising $1 \mathrm{M} \mathrm{HNO}_{3}$ and trace amounts of ${ }^{152} \mathrm{Eu}$ and ${ }^{241} \mathrm{Am}$. The samples were centrifuged for $5 \mathrm{~min}$ and aliquots of $200 \mu \mathrm{L}$ were taken from both phases and measured with a $\gamma$ ray spectrometer equipped with a high-purity germanium detector (HPGe) (EG\&G Ortec).

All HPGe detectors used in the study were equipped with the Gamma Vision Software (EG\&G Ortec) and the $\gamma$-peaks at $59.5 \mathrm{keV}$ and $121.8 \mathrm{keV}$ were examined for ${ }^{241} \mathrm{Am}$ and ${ }^{152} \mathrm{Eu}$, respectively. The distribution ratio $(D)$ was measured as the ratio between the radioactivity of the isotope in the organic and the aqueous phase.

\section{Results and discussion}

Due to the long total time of irradiation with the low dose rate, it was necessary to establish the stability of the solvent as a function of time. The reference solution, kept at a remote distance from the $\gamma$-source but otherwise under the same conditions regarding temperature, light etc., showed no change in distribution ratio for ${ }^{241} \mathrm{Am}$ or ${ }^{152} \mathrm{Eu}$, see Fig. 2, hence it can be concluded that the solvent is stable towards ageing, at least up to $5400 \mathrm{~h}$ ( $225 \mathrm{~d}$ ).

Figs. 3 and 4 illustrate how the distribution ratios (Am or $\mathrm{Eu})$ for the irradiated solvents change with the absorbed dose. The value on the $y$-axis represents $D$ as the percentage of the starting value: that is the $D$ at time zero. The solvent that was exposed to the low dose rate does not show a trend of either decreasing or increasing distribution ratios but instead the value fluctuates around $100 \%$. This indicates that the solvent is rather resistant towards radiolysis. The solvent

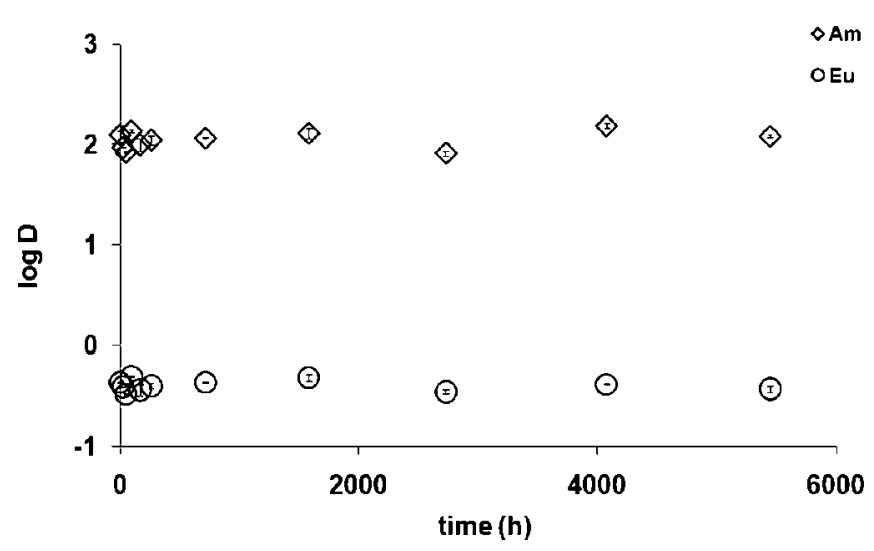

Fig. 2. $\log D$ (Am and Eu) for an unirradiated solution at various times after the start of the experiments. The organic phased comprised $0.01 \mathrm{M}$ MF2-BTBP in cyclohexanone and the aqueous phase comprised $1 \mathrm{M} \mathrm{HNO}_{3}$ with trace amounts of ${ }^{152} \mathrm{Eu}$ and ${ }^{241} \mathrm{Am}$. The total time of irradiation was $5400 \mathrm{~h}$ for the experiment with the low dose rate and $84 \mathrm{~h}$ for the experiment with high dose rate. For triplicates, uncertainties represent one standard deviation based on the triple sample. In the case of double samples, uncertainties were calculated using error propagation based on measurement statistics. 


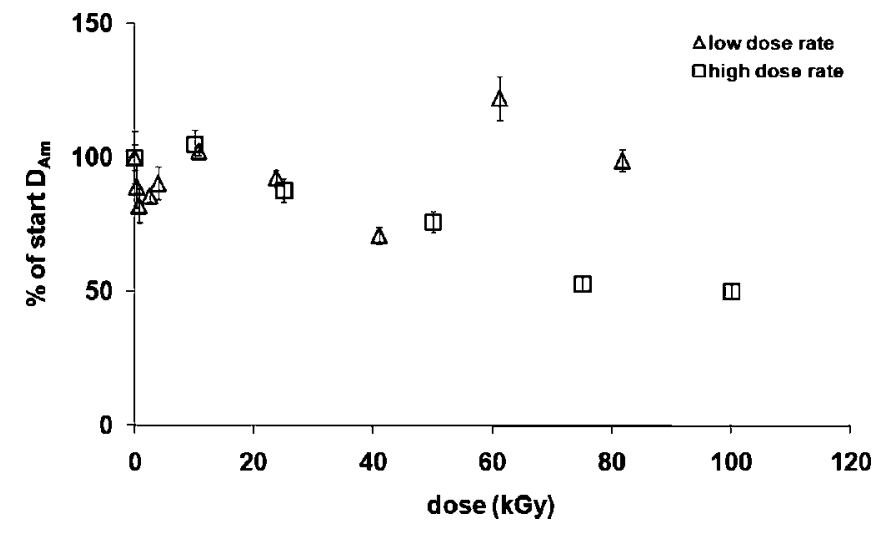

Fig. 3. Percent of the initial value for $D_{\mathrm{Am}}$ for the organic solvent irradiated at two different dose rates. The organic phased comprised $0.01 \mathrm{M}$ MF2-BTBP in cyclohexanone and the aqueous phase comprised $1 \mathrm{M} \mathrm{HNO}_{3}$ and trace amounts of ${ }^{152} \mathrm{Eu}$ and ${ }^{241} \mathrm{Am}$. The total time of irradiation was $5400 \mathrm{~h}$ for the experiment with the low dose rate and $84 \mathrm{~h}$ for the experiment with high dose rate. Uncertainties for low dose rate experiments represent one standard deviation based on the triple sample. Uncertainties for the high dose rate experiments were calculated using error propagation based on measurement statistics.

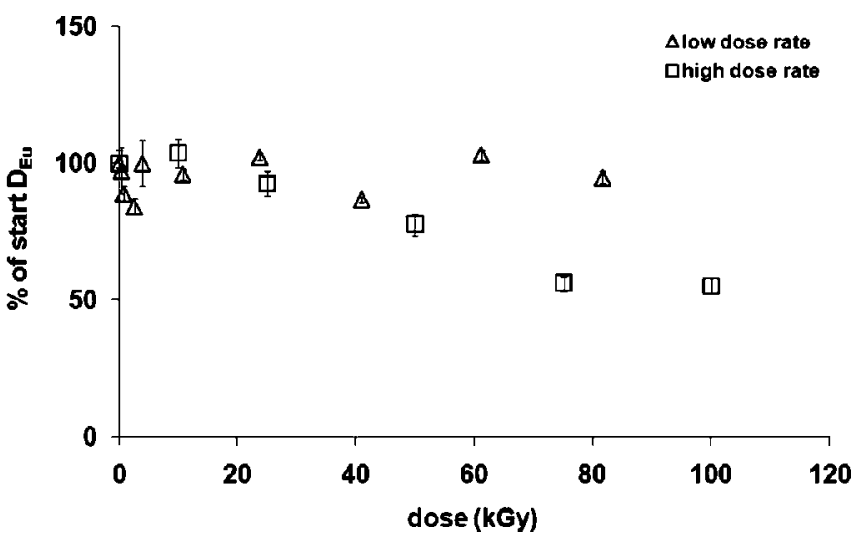

Fig. 4. Percent of the initial value for $D_{\mathrm{Eu}}$ for the organic solvent irradiated with two different dose rates. The organic phase comprised $0.01 \mathrm{M}$ MF2-BTBP in cyclohexanone and the aqueous phase comprised $1 \mathrm{M} \mathrm{HNO}_{3}$ and trace amounts of ${ }^{152} \mathrm{Eu}$ and ${ }^{241} \mathrm{Am}$. The total time of irradiation was $5400 \mathrm{~h}$ for the experiment with the low dose rate and $84 \mathrm{~h}$ for the experiment with high dose rate. Uncertainties for low dose rate experiments represent one standard deviation based on the triple sample. Uncertainties for the high dose rate experiments were calculated using error propagation based on measurement statistics.

that was exposed to a higher dose rate initially shows no significant change but after between 50 and $70 \mathrm{kGy}$ a decrease in distribution ratio can be observed. Thus the solvent seems to be more affected by the higher dose rate. Both metals seem to be affected to the same extent by the irradiation, thus the separation factor between $\mathrm{Am}$ and $\mathrm{Eu}\left(\mathrm{SF}_{\mathrm{Am} / \mathrm{Eu}}\right)$ remains at approximately the same level. This is the most common behaviour for BTBPs $[8,13,18]$. However, a noticeable change in $\mathrm{SF}_{\mathrm{Am} / \mathrm{Eu}}$ was reported for a solvent containing C5-BTBP dissolved in cyclohexanone [23, 24]. For Am, the extraction decreased much more than for Eu, resulting in $\mathrm{a} \mathrm{SF}_{\mathrm{Am} / \mathrm{Eu}}$ that was decreasing from $\sim 150$ to $\sim 40$ after a received dose of $20 \mathrm{kGy}$ [23].

The distribution ratios at the start of the experiments $(t=0)$ were around 110 for americium and around 0.5 for europium. It should be kept in mind that equilibrium had not been reached for europium in the low dose rate experiments.
As described previously, some radiochemical reactions may be dose rate dependent while others may be not. Dose rate dependent reactions are generally secondary [15,25]; i.e., reactions between for example a solute molecule and a radical species formed in a primary process. The conclusion that can be reached from this study is that at least some of the degradation processes seem to be dose rate dependent, since the change in extracting capacity varies between the two sets of experiments. This indicates that the degradation processes affecting the extracting capacity of the ligand are to some extent secondary, hence not involving the incoming radiation directly.

The relative concentration of MF2-BTBP to cyclohexanone is very small ([MF2-BTBP]/[cyclohexanone] $\approx 5 \times 10^{-4}$ ), suggesting that the vast majority of direct interactions take place between the incoming radiation and cyclohexanone molecules. Thus, the degradation of the BTBP molecule is likely caused by reactive species formed in the radiolysis of cyclohexanone. The products resulting from gamma irradiation of cyclohexanone has been reported [26] and the major products beside reactive intermediates such as radicals and ions were dimers and polymers, 5-hexenal, hydrogen, cyclohexanol, carbon monoxide, cyclohexenone and 1-pentene. In addition, several minor products resulting from the radiolysis of cyclohexanone were also reported [23]. When increasing the dose, the yields of polymer and cyclohexanol seemed to increase while the yields of dimers, 5-hexenal and cyclohexenone decreased [26]. The yield of hydrogen and the yield of carbon monoxide were slightly decreasing and increasing, respectively, with dose [26]. As mentioned in the theory section, the production of these stable degradation products may also be affected by the dose rate [14]. None of the reported long-lived products are very likely to react with the BTBP molecules, however, several of the reaction mechanisms leading to these products involve cyclohexanone radical anions and hydroxy-cyclohexyl radicals [27] and these could potentially react with BTBP molecules.

The different behaviours by the two systems could be caused by other factors than the high and low dose rate. The possible ageing with time of the system was ruled out based on the measurements with a reference solution, but there might be other aspects connected to the difference in total time of irradiation. The solution exposed to the low dose rate was in contact with oxygen for a longer time than the high dose rate solution. Although the glass bottle containing the solution was equipped with a lid, this was removed at each sampling and the solution was in direct contact with the oxygen in the air. Presence of oxygen has proven to decrease the radiolytic effect on nitrogen-containing compounds irradiated in the presence of aqueous $\mathrm{HNO}_{3}$, by oxidizing $\mathrm{HNO}_{2}$ formed from $\mathrm{HNO}_{3}$ [28]. The solutions in this study were irradiated in absence of $\mathrm{HNO}_{3}$ (or any other aqueous phase). The degradation of solid polypropylene was accelerated when oxygen was present during $\gamma$-irradiation compared to irradiation in the absence of oxygen [29]. A possible reaction between irradiated organic solutions and oxygen might be that between hydrocarbon radicals, formed by chain cleavage caused by $\gamma$-irradiation, and $\mathrm{O}_{2}$ present in surrounding air. In summary, $\mathrm{O}_{2}$ can either protect the system or enhance certain reactions and the influence depends 
on factors such as the solute, experimental conditions and the specific reaction studied [30].

The temperature during the two sets of irradiations was slightly different and this may affect the degradation reactions. Generally, a higher temperature results in higher yields of radiation-chemical transformations in organic compounds [31]. In addition, secondary reactions and diffusion of reactive species in the media can be affected. The temperature during the irradiations with the ${ }^{60} \mathrm{Co}$ source was $20 \pm 1{ }^{\circ} \mathrm{C}$, while in the cooling pond the temperature was around $25^{\circ} \mathrm{C}$.

Another factor that differs between the two systems is the mean energy of the $\gamma$-rays. For the low dose rate the average photon energy was $1.2 \mathrm{MeV}$ while the mean energy for the higher dose was $0.8 \mathrm{MeV}$. As mentioned previously, $\gamma$-rays interact with matter in three different ways: photoelectric effect, Compton effect and pair production, and the proportion of the different interactions depends on the energy of the photons. For pair production to occur the minimum photon energy must be $1.02 \mathrm{MeV}$. For $1.2 \mathrm{MeV} \gamma$-rays the energy is practically entirely absorbed via Compton effect while for $\gamma$-rays with lower energy a larger part interacts via photoelectric effect [32]. This might affect the energy composition of electrons present in the solution.

\section{Conclusion}

It was observed that a solution containing $0.01 \mathrm{M}$ MF2BTBP in cyclohexanone reacted differently, in terms of metal ion distribution ratios, when irradiated with two different dose rates. The extraction of americium and europium decreased with dose for the solution being irradiated with the high dose rate $(\sim 1.2 \mathrm{kGy} / \mathrm{h})$. For the low dose rate $(\sim 15 \mathrm{~Gy} / \mathrm{h})$ the extraction was more or less unchanged with dose. Thus, an effect of the dose rate was observed but further studies are required to establish if the different dose rates also yielded different degradation products.

Acknowledgment. The authors wish to acknowledge the European Union Project EUROPART (Project FI6W-CT-2003-508854) and the Swedish Nuclear Fuel and Waste Management Co. for their financial support. A special thanks to the unknown reviewers for valuable comments.

\section{References}

1. Madic, C., Hudson, M. J., Liljenzin, J.-O., Glatz, J. P., Nannicini, R., Facchini, A., Kolarik, Z., Odoj, R.: New partitioning techniques for minor actinides. Final Report, NEWPART European Union project FI4I-CT-96-0010, European Commission Project report EUR 19149 (2000).

2. Madic, C., Testard, F., Hudson, M. J., Liljenzin, J.-O., Christiansen, B., Ferrando, M., Facchini, A., Geist, A., Modolo, G., Gonzalez-Espartero, A., De Mendoza, J.: PARTNEW New Solvent Extraction Processes for Minor Actinides. Final Report, European Union project FIKW-CT-2000-00087, Report CEA-R6066 (2004).

3. Madic, C., Hudson, M. J., Baron, P., Ouvrier, N., Hill, C., Arnaud, F., Espartero, A.G., Desreux, J. F., Modolo, G., Malmbeck, R., Bourg, S., De Angelis, G., Uhlir, J.: EUROPART: European research programme for Partitioning of minor actinides within high active wastes issuing from the reprocessing of spent nuclear fuels. $9^{\text {th }}$ Information Exchange Meeting on Actinide and
Fission Product Partitioning and Transmutation, Nîmes, France, Sept. 25-29 (2006).

4. Madic, C., Hudson, M. J., Liljenzin, J.-O., Glatz, J.-P., Nannicini, R., Facchini, A., Kolarik, Z., Odoj, R.: Recent achievements in the development of partitioning processes of minor actinides from nuclear wastes obtained in the frame of the NEWPART European Programme (1996-1999). Progr. Nucl. Energ. 40(3-4), 523-526 (2002).

5. Madic, C., Hudson, M. J.: High level liquid waste partitioning by means of completely incinerable extractants. Final Report, European Commission contract No FI2W-CT91-0112, EUR 18038 (1998).

6. Ekberg, C., Fermvik, A., Retegan, T., Skarnemark, G., Foreman, M. R. S., Hudson, M. J., Englund, S., Nilsson, M.: An overview and historic look back at the solvent extraction using nitrogen donor ligands to extract and separate An(III) from Ln(III). Radiochim. Acta 96(3-4), 225-233 (2008).

7. Drew, M. G. B., Foreman, M. R. S. J., Hudson, M. J., Madic, C: 6,6'-bis-(5,6-dialkyl-[1,2,4-]triazin-3-yl)-[2,2]bipyridyl the first example of a new class of quadridentate heterocyclic extraction reagents for the separation of americium(III) and europium(III). Inorg. Chem. Commun. 8, 239-241 (2005).

8. Nilsson, M., Ekberg, C., Foreman, M., Hudson, M., Liljenzin, J.-O., Modolo, G., Skarnemark, G.: Separation of actinides(III) from lanthanides(III) in simulated nuclear waste streams using 6,6'-bis-(5,6-dipentyl[1,2,4]triazin-3-yl) [2,2']bipyridinyl (C5-BT$\mathrm{BP})$ in cyclohexanone. Solv. Extr. Ion Exch. 24(6), 823-843 (2006).

9. Geist, A., Hill, C., Modolo, G., Foreman, M. R. S. J., Weigl, M., Gompper, K., Hudson, M. J., Madic, C.: 6,6'-bis(5,5,8,8-tetramethyl-5,6,7,8-tetrahydro-benzo[1,2,4]triazin-3-yl)[2,2]bipyridine, an effective extracting agent for the separation of americium(III) and curium(III) from the lanthanides. Solv. Extr. Ion Exch. 24(4), 463-483 (2006).

10. Nilsson, M., Andersson, S., Ekberg, C., Foreman, M. R. S., Hudson, M. J., Skarnemark, G.: Inhibiting radiolysis of BTP molecules by addition of nitrobenzene. Radiochim. Acta 94(2), 103-106 (2006).

11. Strom, D. J.: Dose-Rate Dependence of High-Dose Health Effects in Humans from Photon Radiation with Application to Radiological Terrorism. Prepared for the U.S. Department of Energy under Contract DE-AC06-76RLO 1830 (2005).

12. Chatterjee, A.: In: Radiation Chemistry - Principles and Applications. (Farhataziz, Rodgers, M. A. J., eds.) VCH Publishers Inc., New York (1987), pp. 3-10.

13. Hudson, M. J., Boucher, C. E., Braekers, D., Desreux, J. F., Drew, M. G. B., Foreman, M. R. S. J., Harwood, L. M., Hill, C., Madic, C., Marken, F., Youngs, T. G. A.: New bis(triazinyl) pyridines for selective extraction of americium(III). New J. Chem. 30, 11711183 (2006).

14. Swallow, A. J.: In: Radiation Chemistry - Principles and Applications. (Farhataziz, Rodgers, M. A. J., eds.) VCH Publishers Inc., New York (1987), Chapt. 11.

15. Rice, R. N., Gorin, G., Raff, L. M.: Radiolysis of compounds in solution. Model calculations on the effects of concentration, impurity, and dose rate. J. Phys. Chem. 79(25), 2717-2722 (1975).

16. Buxton, G. V.: In: Radiation Chemistry - Principles and Applications. (Farhataziz, Rodgers, M. A. J., eds.) VCH Publishers Inc., New York (1987), Chapt. 10.

17. Foreman, M. et al.: Unpublished work (2008).

18. Hill, C., Berthon, L., Madic, C.: Study of the stability of BTP extractants under radiolysis. GLOBAL, Tsukuba, Japan, Oct. 9-13 (2005).

19. Retegan, T. et al.: Unpublished work (2008).

20. Denecke, M. A., Rossberg, A., Panak, P. J., Weigl, M., Schimmelpfennig, B., Geist, A.: Characterization and comparison of $\mathrm{Cm}$ (III) and $\mathrm{Eu}(\mathrm{III})$ complexed with 2,6-di(5,6-dipropyl-1,2,4triazin-3-yl)pyridine using EXAFS, TRFLS, and quantumchemical methods. Inorg. Chem. 44(23), 8418-8425 (2005).

21. Geist, A.: Personal communication (2008).

22. Retegan, T., Ekberg, C., Englund, S., Fermvik, A., Foreman, M. R. S., Skarnemark, G.: The behaviour of organic solvents containing C5-BTBP and $\mathrm{CyMe}_{4}$-BTBP at low irradiation doses. Radiochim. Acta 95(11), 637-642 (2007). 
23. Fermvik, A., Ekberg, C., Foreman, M. R. S., Retegan, T., Skarnemark, G.: The effect of irradiation on extraction of various metals by C5-BTBP. Solvent Extraction: Fundamentals to Industrial Applications, Proceedings of ISEC 2008, Tucson, AZ, Sept. 15-19 (2008), Vol. 1, pp. 551-556.

24. Nilsson, M.: Screening Investigations of Novel Nitrogen Donor Ligands for Solvent Extraction. Ph.D. Thesis, Chalmers Technical University, Gothenburg (2005), ISBN 91-7291-699-0.

25. Abramson, F. P., Firestone, R. F.: Combined effects of dose rate and temperature in the radiolysis of liquid chloroform. Application of homogenous kinetics to the radiolytic system. J. Phys. Chem. 70(11), 3596-3605 (1966).

26. Singh, A., Freeman, G. R.: Radiolysis of cyclohexanone: I. Pure liquid. Can. J. Chem. 42(8), 1869-1876 (1964).

27. Alipour, E., Vidril, D., Micheau, J. C., Paillous, N., Lattes, A., Gilles, L., Mathieu, J.: Mechanism of the $\gamma$-radiolysis of 2-propanol solutions of cyclohexanones. Tetrahedron 39(17), 2807-2813 (1983).
28. Mezhov, E. A., Kulikov, I. A., Teterin, E. G.: Study of extraction of palladium from nitric acid solutions with nitrogen-containing compounds, as applied to recovery of fission palladium from spent nuclear fuel of nuclear power plants: 2. Effect of radiation on palladium recovery and condition of extraction systems. Radiochemistry 44(2), 141-145 (2002).

29. Gorelik, B. A., Kolganova, I. V., Matisová-Rychlá, L., Listvojb, G. I., Drabkina, A. M., Golnik, A. G.: Effect of oxygen on the degradation of polypropylene initiated by ionizing irradiation. Polym. Degrad. Stab. 42(3), 263-266 (1993).

30. Stein, G.: Some aspects of the radiation chemistry of organic solutes. Faraday Discuss. 12, 227-234 (1952).

31. Milinchuk, V. K.: Introduction. In: Organic Radiation Chemistry Handbook. (Milinchuk, V. K., Tupikov, V. I., eds.) Ellis Horwood Limited, Chichester, UK (1989).

32. Choppin, G., Liljenzin, J.-O., Rydberg, J.: In Radiochemistry and Nuclear Chemistry. $3^{\text {rd }}$ Edn., Butterworth-Heinemann, Woburg (2002), Chapt. 6. 